\title{
Computational Modelling of a Novel Three Dimensional Ground Mat for 33/11kV Central Switching Station
}

\author{
M. Hariharan \\ Indira Gandhi Centre for Atomic Research \\ Kalpakkam, 603102 - Tamilnadu, India
}

\author{
S. Roger \\ Department of Electrical and Electronics \\ Engineering PSG College of Technology, \\ Coimbatore, Tamilnadu, India
}

\begin{abstract}
This paper presents a novel concept being followed in the computational design of a ground mat for a $33 / 11 \mathrm{kV}$ central switching station at dry loose sandy soil containing high soil resistivity. The area available for mat is less and unsymmetrical. In areas where the soil resistivity is high and the space available for substation ground mat is less, it may not be possible to meet the expected safe touch and step voltage criteria with conventional ground mat design. A methodical analysis of design of three dimensional ground mat is performed by adopting wenner four pin method of computation. The major advantage behind this model is that it inherently develops a safe touch and step potential with the electrical apparatus considerably even at unusual working conditions. Since the location has high resistive soil and multilayered, a novel three dimensional ground mat with controlled safe region is designed and analyzed with Auto Grid Pro (application for grounding studies) software.
\end{abstract}

\section{Keywords}

Ground Potential Rise (GPR), Touch Potential, Step Potential, Ground Mat, Soil Resistivity, Grounding Grid, Ground Rods, Grounding Electrodes.

\section{INTRODUCTION}

A $11 \mathrm{kV}$ substation at our project site is being built to feed existing and upcoming facilities. It is developed like a green field project as presently there is no full-fledged substation at the said location as the conventional ground mats failed to satisfy the safety of the substation. The worldwide researchers are trying to understand the design criteria for a optimal safe operating region under optimal voltage and at high voltage levels with the $3 \mathrm{D}$ ground mat, the database in the literature is scanty. There has been a necessity to design a new three dimensional ground mat system to ensure the safety of the switching station. In the due course of design of the three dimensional ground mat soil resistivity measurements have been taken and the areas of unsafe zones of the substation has been identified, these values have been found challenging. Further the area available for commissioning the ground mat is very less and certainly unsymmetrical about the center of the switching station. This paper presents various options and final design along with the analysis of GPR for typical ground mat designs.

\section{GROUND MAT}

During typical ground fault conditions, the rate of flow of current to earth will produce potential gradients in and around the substation [1]. A ground mat is a system of closed bare spaced conductors that are connected to the electrical apparatus in a substation and are often placed in shallow depths, in order to minimize the danger of the exposure to high step or touch voltages in a critical operating area. The primary objective in the design of substation grounding is to provide safe conditions for the person operating in and around the substation. Therefore, the grounding system must be designed in such a way as

a. To provide means to carry electric currents into the earth under normal and fault conditions without exceeding any operating and equipment limits or adversely affecting continuity of service. (Limit the potential rise of the substation ground mat to an acceptable value for any possible fault condition) [2].

b. To assure that a person in the vicinity of grounded facilities is not exposed to the danger of critical electric shock. (Limit the resulting step, touch and transfer potentials in and around the substation to an acceptable value) [3].

The surface potentials are approximately proportional to the grid potential rise and both are determined by the current flow from the grounding grid to the earth [4].

\section{NEED FOR COMPUTER ALGORITHMS IN GROUND MAT DESIGN}

1. Computational algorithms are mainly used to find out the unsafe zones in the substation and vicinity of substation. With the conventional method, it is not at all possible to identify the existence of unsafe zones.

2. A two-layer or multilayered soil model is preferred in computer algorithm due to significant variations in soil resistivity. Approximate methods of calculations are applicable only for homogeneous soil models [5].

3. Uneven grid conductor or ground rod spacing cannot be analyzed using the conventional methods of calculation.

\section{ALGORITHM FOR DESIGN OF A 3D} GROUNT MAT

Various steps have been taken into consideration for designing the ground mat

1. Field surveys have been conducted at the targeted areas where the proposed substation is going to get erected for accurate estimation of homogeneous soil resistivity.

2. Approximate measurement of grid/conductor sizing has been taken into consideration.

3. As an approximation the value of fault current is considered to as same as the value of grid current.

4. Design parameters such as the value of soil resistivity, fault current were inputted to the ground 
mat design software to determine the exact value of the fibrillation current.

5. Geometrical configurations, burial depth and physical dimensions of the ground mat is approximated.

6. The datas that were being recorded is initiated with the design algorithm to compute the required design.

7. Post obtaining the results from the iterated algorithm the safe and unsafe regions of the earth mat to be erected outside the switching station has been identified.

8. If the step and touch potentials are not within the safe limits as calculated by the computer program, the ground mat design is being modified and processed again, till a unique $3 \mathrm{D}$ model with safe operating region is obtained.

\section{MODELLING ASPECTS OF GROUND MAT AN OVERVIEW}

The parameters that primarily govern the performance of grounding system are:

1. Soil resistivity in the nearest vicinity of the embedded grounding conductors.

2. Area of conductor sizing occupied with the ground mat.

3. Fault level and duration of the grounding system periphery.

4. Surface area governing the geometry of the mat.

\section{A) Soil Resistivity Measurements at \\ Switchyard:}

The Wenner four-pin method, as described in IEEE Std 81 clause 7.2.3, is used for measurement of soil resistivity in the substation [6]. The soil in the region is non-homogeneous, multilayered and has high resistivity and the resistivity level of soil that has been computed is depicted in Table 1. These details were being fed to the computational algorithm.

\section{B) Conductor Sizing of Ground Mat:}

i) Copper Conductor:

$1 \mathrm{~s}$ current rating $=205 \mathrm{~A} / \mathrm{mm}^{2}$

Fault Current $=10 \mathrm{kA}$

Required Conductor Size $=$ Fault Current $/ 1$ s current rating

$=10 \times 1000 / 205$

$$
=48.8 \mathrm{~mm}^{2}
$$

From the above calculation $48.8 \mathrm{~mm}^{2}$ of copper conductor is sufficient w.r.t the current rating of the conductor.

Based on availability of material at the switchyard site, 95 $\mathrm{mm}^{2}$ tinned stranded copper conductor is chosen. Computational analysis was carried out only with $95 \mathrm{~mm}^{2}$ tinned stranded copper conductor.

\section{ii) Steel Conductor:}

As steel conductors are not readily available in the market, $95 \mathrm{~mm}^{2}$ ACSR conductors were used for ground mat analysis and it is equivalent to the area of steel conductors which is installed outside the switching station.

Steel conductor equivalent to $95 \mathrm{~mm}^{2}$ copper $=($ Resistivity of steel conductor / Resistivity of copper conductor) x 95

$$
\begin{aligned}
& =\left(1.3800 \times 10^{-07} / 1.7241 \times 10^{-08}\right) \times 95 \\
& =760.39 \mathrm{~mm}^{2}
\end{aligned}
$$

Hence $75 \mathrm{~mm}$ x $10 \mathrm{~mm}$ standard galvanized steel conductors will be installed outside the substation.

\section{C) System Fault level and Duration:}

The Maximum possible fault current present at $11 \mathrm{kV}$ Bus at the substation is $7.9 \mathrm{kA}$. Hence for Ground mat design purpose, $10 \mathrm{kA}$ is considered as the approximate fault level/maximum grid current with fault clearance time of 0.5 seconds.

Table 1: Table depicting the resistance and apparent resistivity measured using wenner four-pin method

\begin{tabular}{|l|l|l|l|l|}
\hline S. No. & $\begin{array}{l}\text { Distance } \\
\text { between } \\
\text { electrodes } \\
\text { in } \mathbf{~ m}\end{array}$ & $\begin{array}{l}\text { Measured } \\
\text { resistance } \\
\text { in } \mathbf{\Omega}\end{array}$ & $\begin{array}{l}\text { Depth of the } \\
\text { electrodes in } \\
\text { m }\end{array}$ & $\begin{array}{l}\text { Apparent } \\
\text { resistivity of the } \\
\text { soil } \\
\text { in } \mathbf{\Omega} \text { m }\end{array}$ \\
\hline 1 & 0.1 & 6000 & 0.35 & 7486 \\
\hline 2 & 0.3 & 1500 & 0.35 & 4978 \\
\hline 3 & 0.7 & 760 & 0.35 & 4403 \\
\hline 4 & 1 & 500 & 0.35 & 3711 \\
\hline 5 & 3 & 56 & 0.35 & 1081 \\
\hline 6 & 7 & 51 & 0.35 & 2257 \\
\hline 7 & 10 & 10 & 0.35 & 634 \\
\hline 8 & 30 & 2100 & 0.35 & 396084 \\
\hline 9 & 70 & 1720 & 0.35 & 756833 \\
\hline 10 & 100 & 620 & 0.35 & 38723 \\
\hline
\end{tabular}




\begin{tabular}{|l|l|l|l|l|}
\hline 11 & 200 & 360 & 0.35 & 452574 \\
\hline 12 & 300 & 56.7 & 0.35 & 106720 \\
\hline
\end{tabular}

\section{RESULTS AND DISCUSSION}

IEEE Std 80 clause 16.2.5 states that "The area of the grounding system is the single most important geometrical factor in determining the resistance of the mat" [7]. The larger the area grounded, the lower the grid resistance and thus the lower the ground potential rise. The soil resistivity is comparatively high at the substation area for which the ground mat design is proposed. Land area that is available at substation for the ground mat is limited.

For unusual working conditions like limited area and high resistivity homogeneous soil, IEEE Std 80 suggests the use of deep-driven ground rods, connection(s) to remote ground mat(s) or adjacent grounding facilities, satellite grid at low resistivity soil and treatments of soil at substation. As none of these options were readily available at this substation area due to the following reasons:

1. The number of deep driven rods required to meet safe critical voltage is high and hence not economical.

2. Treatment of soil with combining material like bentonite powder will not have long life as it gets washed away during rainy season.

3. Connections to adjacent or remote grid will make the other grid unsafe (Red lines on the plot indicates substation.)
4. Satellite grounding at low resistive soil is not feasible as all the nearby area has the same type of soil as present in the switching station.

5. Parallel conductors around the perimeter of the switching station at successively greater depth did not result in appreciable change in safe operating region.

With the parameters obtained so far the ground mat is modelled and analyzed through the computer program. From the result of the analysis unsafe regions were identified and such areas are modified with reduced spacing in ground mat. The modified design of the mat is further analyzed by the computer program by executing multiple iterations such that the design is redefined. The iteration is continued till the safe values are obtained.

The major ground mat designs analyzed with computer program are mentioned below. After multiple iterations the following observations were recorded.

1. Simple ground mats (flat, single layer and equally spaced mat) are unsafe.

2. Unequally spaced mats are unsafe at the edges.

3. To make it safe, mat with smooth and extended edge are difficult to construct and maintain.

4. It is observed that bigger mat is better in achieving safe critical voltage levels.

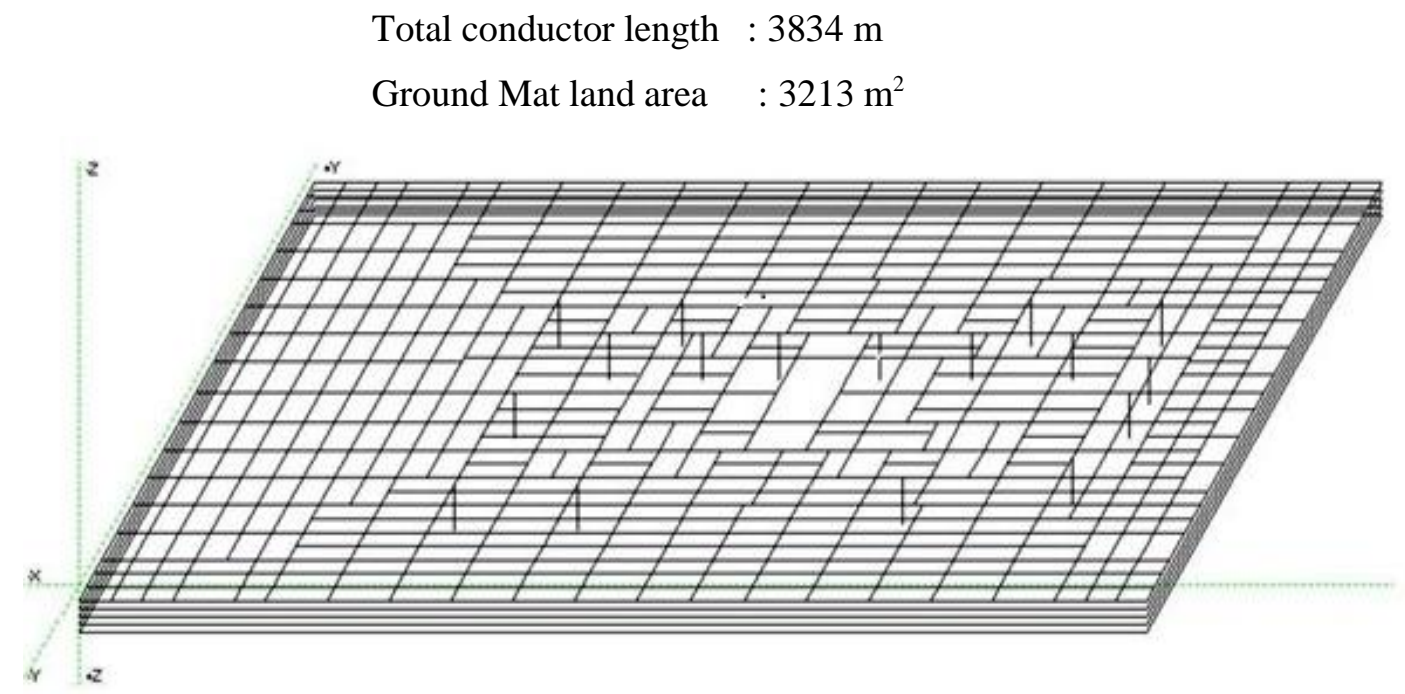

Fig 1: 3D view of ground mat with safe region 


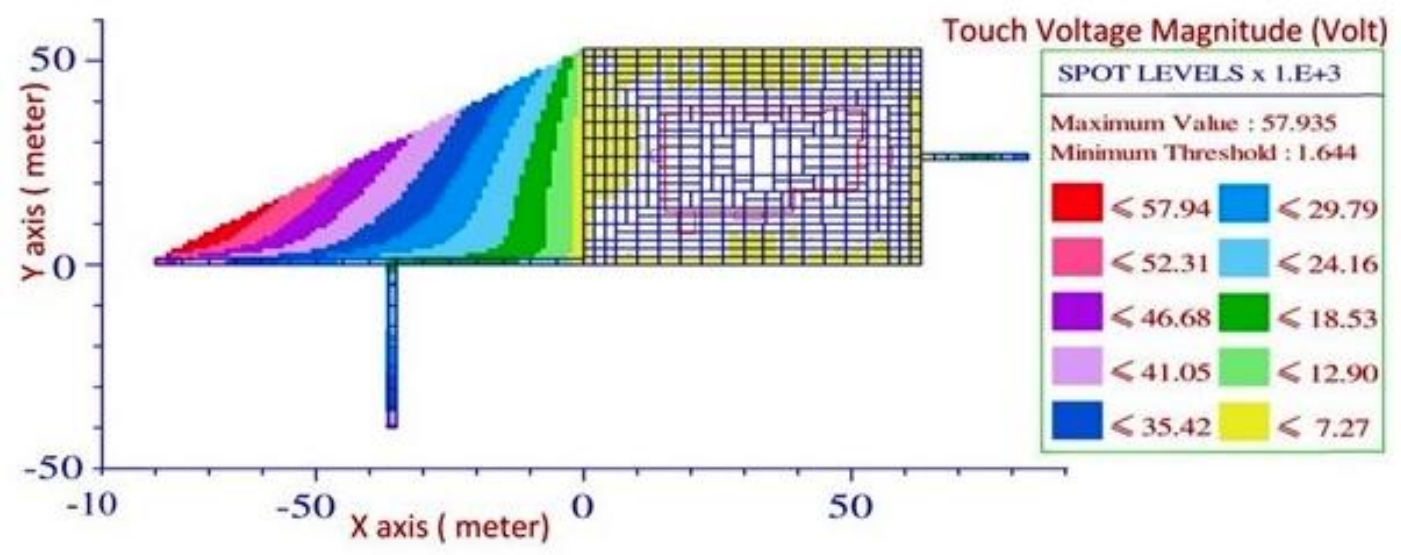

Fig 2: Touch Potential Plot (for Unsafe Region)

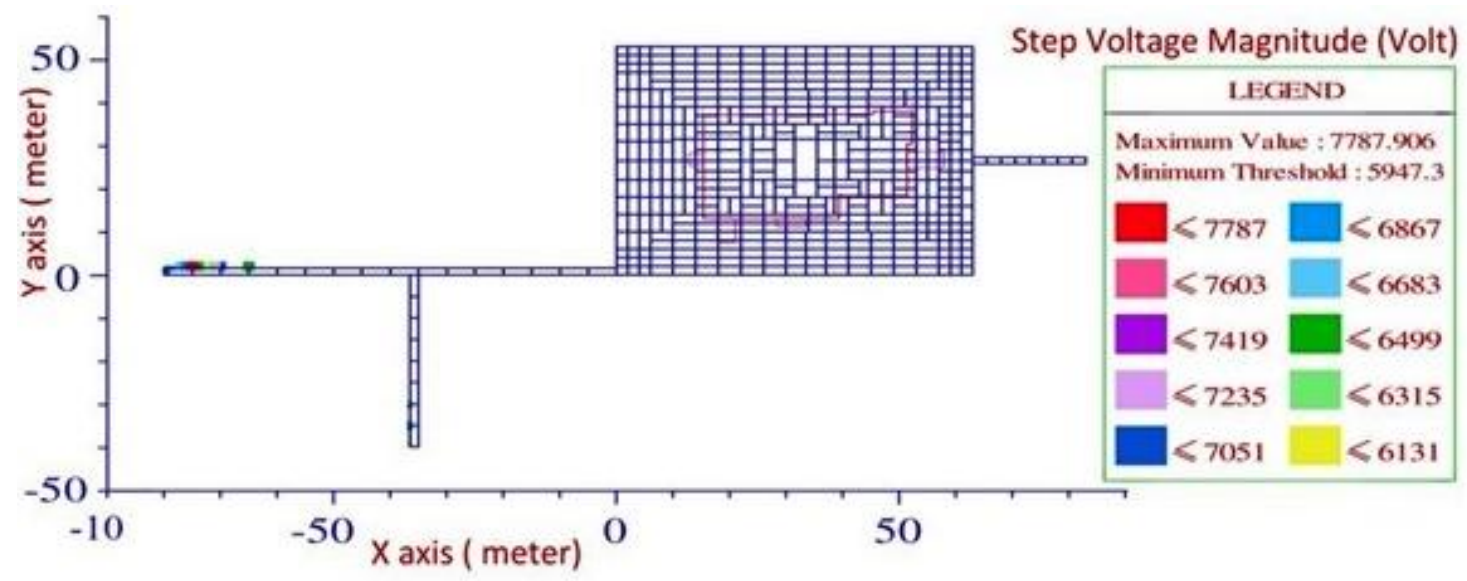

Fig 3: Step Potential plot (for unsafe region)

\section{CONCLUSION}

The computational modelling of a three dimensional ground mat design is presented in this paper. Various configurations and capabilities of the ground mat has been examined and results were being recorded with the switching station where the area of soil resistivity is considerably high. A novel method is developed which will make a safe earth mat even in high soil resistivity conditions. Various methods are analyzed and the detailed results were being presented.

From the above observations it is concluded that a smooth edged mat that is big enough can offer a safe solution. To achieve this in limited area of substation the plane mat is bent and installed vertically. In this way the area occupied by the grid is reduced but not the mat plane size. The vertical portion of the grid behaves like ground electrodes and as a grid. It is observed that unequally spaced three dimensional layered ground mats perform better than regular mat with same quantity of conductor and area. The safe region is controlled by adding layers of mat at specific region in the above mat. Further optimization is done by reducing the size of the mat and extending the mat along cable trench in the substations.

As a scope of the future work this study can be extended to analyze the design capabilities of earth mat in EHV power stations/ generating stations.

\section{ACKNOWLEDGEMENTS}

We are extremely grateful to Mr. L.Subramanyam, Scientific Officer, Head Electrical Works Section (EWS), and Mr. J. Jayakumar, Technical Officer, Department of Atomic Energy (DAE), Indira Gandhi Center for Atomic Research, Kalpakkam for their consistent support and guidance throughout this work.

\section{REFERENCES}

[1] "IEEE Guide for Safety in AC Substation Grounding", IEEE Std 80-2000.

[2] "IEEE Guide for Measuring Earth Resistivity, Ground Impedance, and Earth Surface Potentials of a Grounding System”, IEEE Std 80-2012.

[3] “Code of Practice for Earthing”, IS: 3043 - 1987.

[4] "IEEE Recommended Practice for Industrial and Commercial Power Systems Analysis (Brown Book)", IEEE Std 399-1997.

[5] "IEEE Guide for Measuring Earth Resistivity, Ground Impedance, and Earth Surface Potentials of a Ground System Part 1: Normal Measurements", IEEE Std 811983.

[6] "IEEE Guide for Safety in AC Substation Grounding", IEEE Std 80-1986.

[7] "IEEE Recommended Practice for Determining the 
Electric Power Station Ground Potential Rise and Induced Voltage from a Power Fault", ANSl/IEEE Std.367-1987, IEEE - New York.

[8] K. Sushma Reddy, G. S. Raju, Poonam Upadhyay, "Design of optimal grounding mats for high voltage substation", International Conference on Advances in Power Conversion and Energy Technologies,IEEE, pp 1 $-4,2012$.

[9] Lonnie E. Crawford, M. Shan Griffith," A Closer Look at "the Facts of Life" in Ground Mat Design", IEEE Transactions on Industry Applications, Volume: IA-15, Issue: 3, pp: $241-250,1979$.

[10] B.R.Gupta and B.Thapar, "Impulse Impedance of grounding grids", IEEE transactions on power apparatus and systems, Vol.PAS-99, No.6, Nov-Dec 1980.

[11] R.Velazquez and D.Mukhedkar, "Analytical modeling of grounding electrodes transient behavior", paper presented at, IEEE/PES 1983, summer meeting, Los Angeles, California, July 17-22, 1983.

[12] R. Kosztaluk, et al. "Field Measurements of Touch and Step Voltages", IEEE Trans on power apparatus and systems, Vol PAS -103, No. 11, Nov. 1984.

[13] M.Ramamoorty, M.M.Babu Narayanan, S. Parameswaran, D.Mukhedkar, "Transient Performance of Grounding Grids", IEEE transactions on power delivery, Vol 4, No 4, October 1989.

[14] K. D. Pham, "Design of a safe grounding system for rural electric power distribution Substations" Papers Presented at the 34th Annual Conference on Rural Electric Power, pp: C1/1 - C1/4, 1990.

[15] P. Lipavsky, R. E. Nienaber, "Measurement of ground potential difference at power substations" IEEE Transactions on Power Delivery, Volume: 6, Issue: 1, pp: $6269,1991$. 